\title{
Tartrazine Solution as Dosimeter for Gamma Radiation Measurement
}

\author{
Mohammed Gobara*, Ahmad Baraka \\ Egyptian Armed Forces, Kobbry Elkobba, Cairo, Egypt \\ *E-mail address: m_gobara@yahoo.com
}

\begin{abstract}
In this study, Tartrazine aqueous solution was investigated as a simple low-dose dosimeter in the range of 20-500 Gy for the high ionizing radiation, gamma ray. Gradual bleaching of Tartarzine solution was observed with dose by measuring the absorbance of Tartarzine-solutions at specified wavelength, $\lambda_{\max }=428 \mathrm{~nm}$. Tartrazine concentration $\left(10^{-4}, 5 \times 10^{-4}\right.$ and $\left.10^{-3} \mathrm{M}\right)$ and solution-initial $\mathrm{pH}$ value $(5,7$ and 9) were considered as factors affecting degree of bleaching. It was found that Tartarzine-solution color was diminished gradually with selected dose range due to breakdown of the azo bond. The rate of bleaching increases with the increase of solution-initial $\mathrm{pH}$. Increase of Tartarzine-concentration causes widening of range to which solution is susceptible. The post-irradiated effect (24 hours) was found to cause more bleaching. The sensitivity of Tartrazine solution is not regular with the Tartarzine-concentration and regular with $\mathrm{pH}$.
\end{abstract}

Keywords: Gamma radiation; Degradation; sensitivity; Tartrazine; Dosimeter

\section{INTRODUCTION}

The gamma-induced color bleaching of many organic dyes has been widely investigated. Most of the reported experimental works have been performed in aqueous aerated acidic or alkaline solutions. The decrease of absorbance with irradiation, bleaching, suggests that it can be use as a chemical dosimeter [1-4].

It has been reported that the decolorization could be explained in terms of interaction of radicals $\mathrm{H}^{\cdot}$ and ${ }^{\circ} \mathrm{OH}$ with the dyes in de-aerated aqueous solutions and in terms of $\mathrm{HO}_{2}{ }^{\circ} / \mathrm{O}_{2}{ }^{-}$ and ${ }^{\circ} \mathrm{OH}$ interactions in aerated aqueous solutions. $\mathrm{H}^{\circ}$ is generally associated with the reversible reductive decolorization and the radicals ${ }^{\circ} \mathrm{OH}$ and $\mathrm{HO}_{2}{ }^{\circ} / \mathrm{O}_{2}{ }^{-}$are considered to be the cause of the reversible oxidative decolorization $[5,6]$.

Radiation effect at dose range up to $120 \mathrm{kGy}$ on some dyes in non aqueous solvents such as methyl orange, Congo red, phenol red in acetone and ethanol and dimethylformamide was studied $[7,8]$.

The bleaching of some dyes with different concentrations in non-aqueous solutions indicates that these dyes are promising chemical dosimeters.

Moreover, aqueous solution of methyl red as a dosimeter for gamma radiation at dose range up to $6 \mathrm{KGy}$ was studied. Bleaching of its alkaline and acidic solutions containing 
different amounts of ethanol showed possibility of using these dye as a chemical dosimeter [9].

Tartarzine (known as E102 or FDC Yellow 5) is a synthetic lemon yellow azo-dye used as a food coloring. Its structure is shown in

Figure 1. It is found in many food stuff, soft drinks, instant puddings, flavored chips, cake mixes, custard powder, soups, sauces, ice cream, candy...etc.

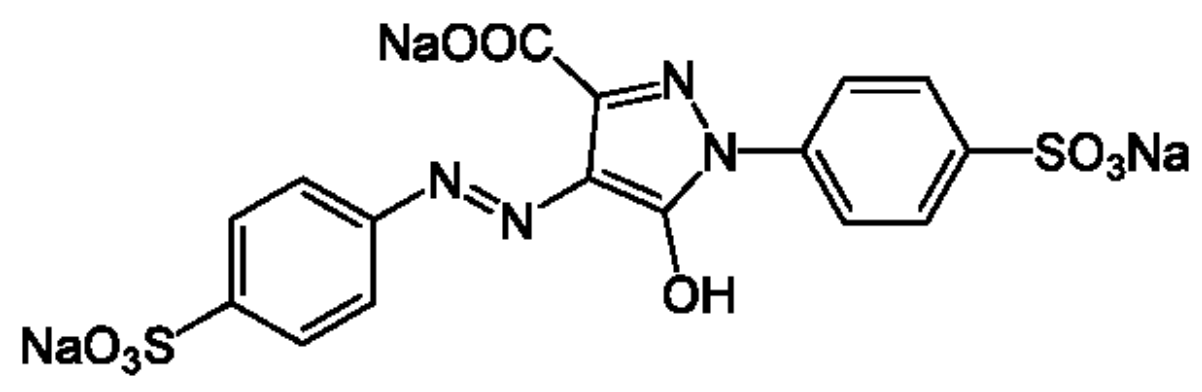

Figure 1. Chemical structure of Tartrazine.

It is also found in some pharmaceutical products and cosmetics such as soaps, hair products, moisturizers, crayons, stamp dyes, vitamins, antacids, medicinal capsules and certain prescription drugs $[5,10,11]$. It is an available and not expensive material.

In the present work, solutions of Tartrazine were investigated as gamma radiation dosimeter. Tartrazine with different concentrations and $\mathrm{pH}$ values were subjected to gamma radiation in the dose range between (20-500 Gy) and then the absorbance of Tartrazine dye in the UV-Vis range were determined.

\section{EXPERIMENTAL}

Tartrazine (from local source, Kamena Co.) and bi-distilled water are used to prepare different solutions of concentrations; $10^{-4}, 5 \times 10^{-4}$ and $10^{-3} \mathrm{M}$. The solutions are then, each, placed in $40 \mathrm{ml}$ plastic vial. The vials are then introduced into gamma cell (Gamma Chamber 5000 / India, dose rate $=2.1 \mathrm{kGy} / \mathrm{hr}$ ) to be exposed to a steady state radiolysis. The dose range studied was $20-500 \mathrm{~Gy}$. Prior to irradiation for each vial, the $\mathrm{pH}$ value was adjusted using $0.1 \mathrm{M} \mathrm{HCl}$ and $0.1 \mathrm{M} \mathrm{NaOH}$ aqueous solutions using Hanna pH-211.

Tartrazine degradation was detected by measuring the absorbance of irradiated samples using Shimadzu UV-160 spectrophotometer. All measurements were carried out at ambient temperature using quartz cells with $1 \mathrm{~cm}$ optical path length. The $\mathrm{pH}$ value for each sample was also determined after gamma irradiation. Figure 2 showed the absorbance spectrum of Tartrazine in UV-Vis. Range with a peak at $428 \mathrm{~nm}$ which is used to determine the concentration of Tartrazine for all samples [12,13,20]. Two set of measurements were performed, the first one immediately after irradiation (within about 10 minutes) and the second one, same samples, on a longer term (after 24 hours). The long term samples were kept after irradiation under normal laboratory conditions in dark. 


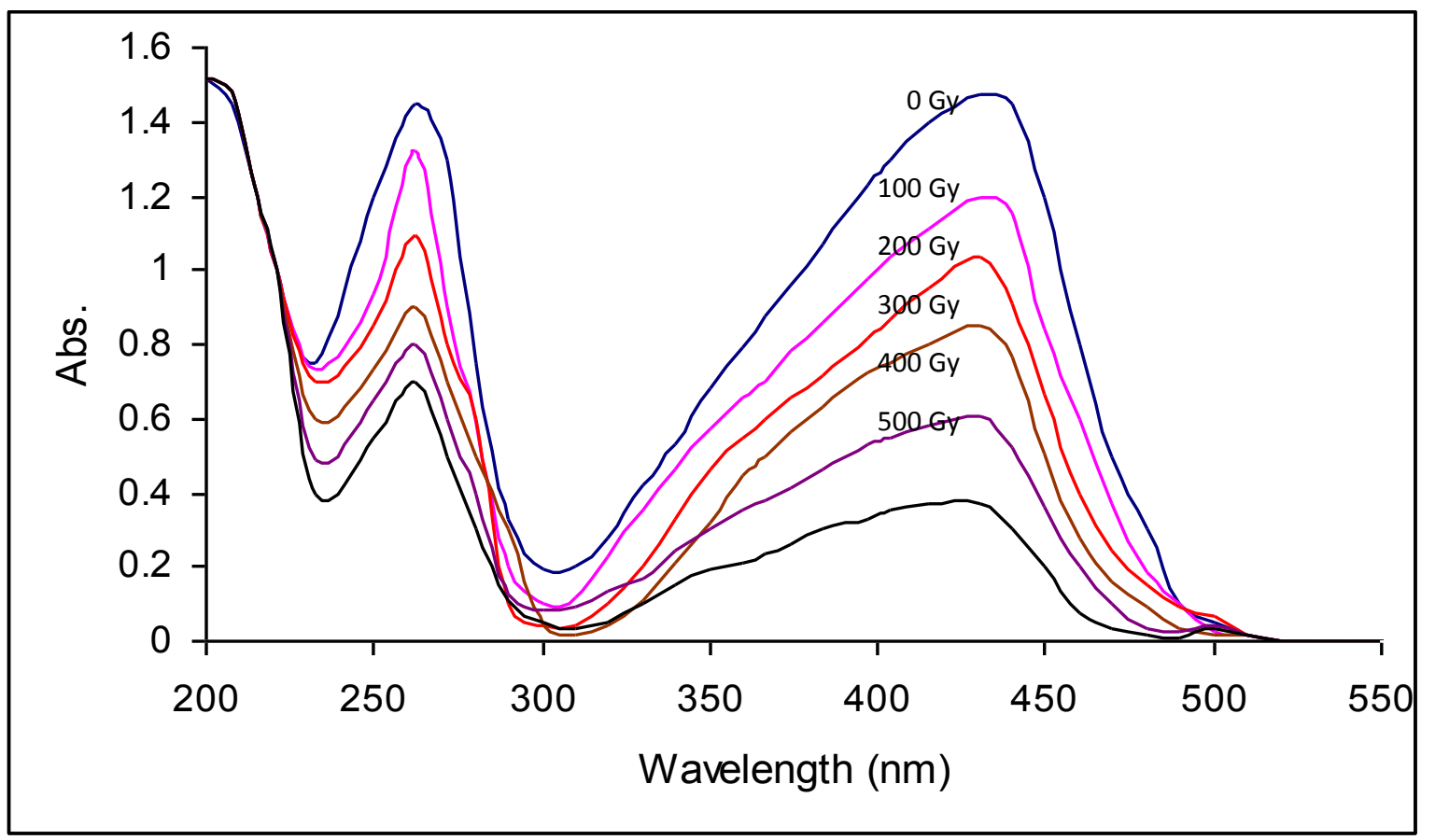

Figure 2. UV-Vis Tartrazine spectra for different doses ( 0 to $500 \mathrm{~Gy})$, Initial concentration $=5 \times 10^{-4}$ $\mathrm{M}$ and $\mathrm{pH}=9$.

\section{RESULTS AND DISCUSSION}

\section{1. Degradation Reactions}

The absorption spectrum of Tartrazine, azo dye, (Figure 2) presents two main peaks, one in near UV $\left(\lambda_{\max }=257 \mathrm{~nm}\right)$ and another one in the visible range $\left(\lambda_{\max }=428 \mathrm{~nm}\right)$. The former peak, at $257 \mathrm{~nm}$, is characteristic to the individual aromatic rings where, the latter one responsible for the yellow color which assigned to $\pi-\pi^{*}$ transition of $\mathrm{N}=\mathrm{N}, \mathrm{C}=\mathrm{N}$ and $\mathrm{C}=\mathrm{O}$ groups [13]. The azo compounds, such as Tartrazine, are usually intensely colored because the diazenediyl linkage $(-\mathrm{N}=\mathrm{N}-)$ brings the two aromatic rings into conjugation. This gives an extended system of delocalization of $\pi$ electrons and allows absorption of light in the visible region [6]. When a reproducible relationship between the absorbance of dye solution and the irradiation dose is observed, the use of this as chemical dosimeter can be proposed. Gamma irradiation causes gradual color bleaching of organic dyes, hence gives a chance for such application.

Figure 3, shows an example of such degradation of Tartrazine (initial concentration $=$ $5 \times 10^{-4} \mathrm{M}, \mathrm{pH}=9$ and doses from 0 to $500 \mathrm{~Gy}$ ). For non de-aerated solution of Tartrazine, the bleaching may be due to oxidative de-colorization reaction with $-\mathrm{N}=\mathrm{N}-$ group (the chromophore moiety in Tartrazine compound) by $\mathrm{HO}_{2}{ }^{\circ} / \mathrm{O}_{2}{ }^{-}$and ${ }^{\circ} \mathrm{OH}$ produced by gamma irradiation of the aqueous solution [7,8]. Figure 3-aand 3-b show the FTIR spectra of Tartrazine solution before and after irradiation $(4 \mathrm{kGy})$ respectively. For the non irradiated sample, stretching vibration peak of $-\mathrm{N}=\mathrm{N}-$ is present at $1560 \mathrm{~cm}^{-1}$ [17]. For the irradiated sample, the peak is not present any more which indicates that oxidative radiolytic products reacted with the chromophore $-\mathrm{N}=\mathrm{N}-$. This result of breakdown of azo bond was reported before [6]. 

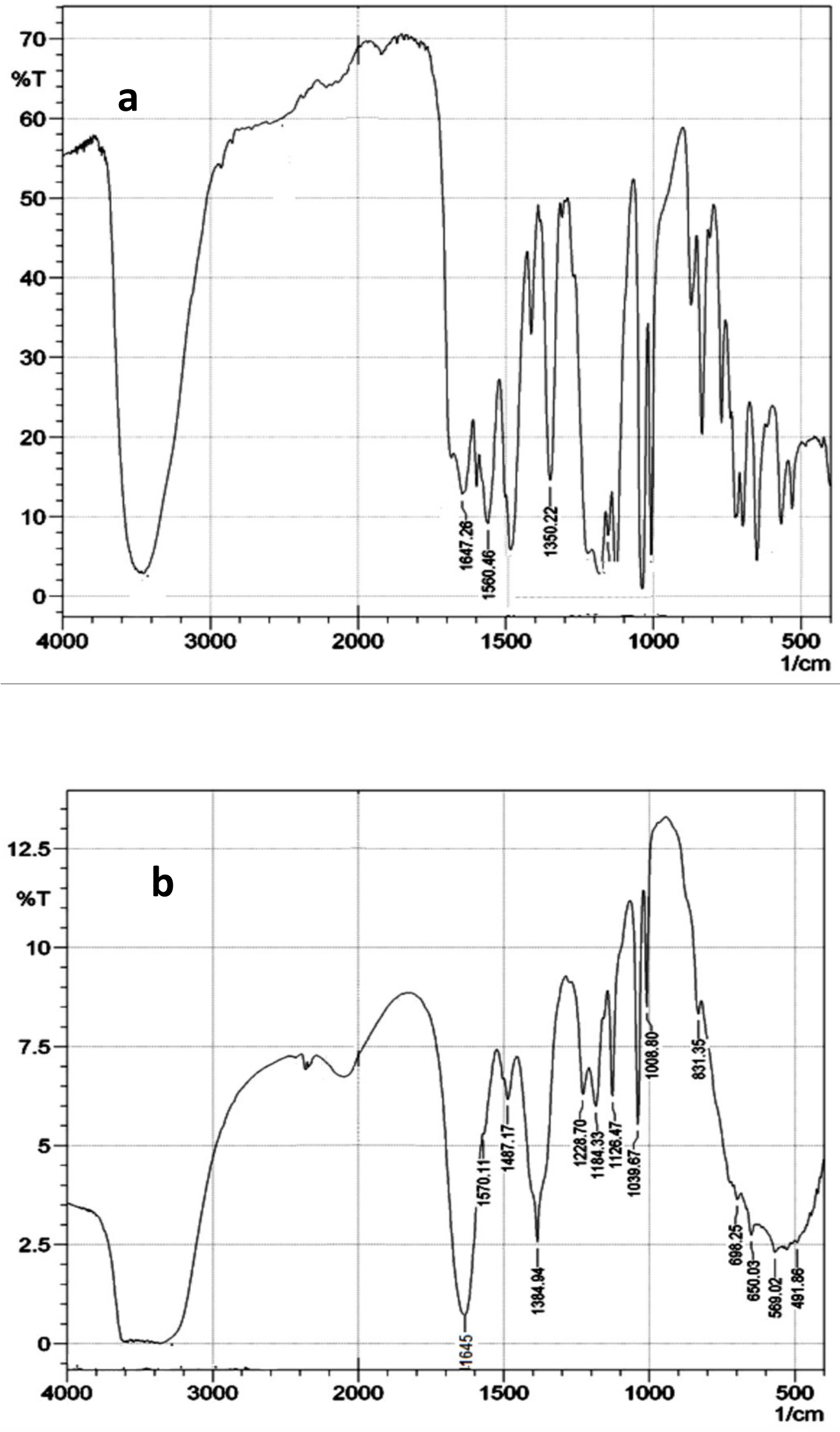

Figure 3. FTIR spectra of Tartarzine aqueous solution (a) before and (b) after irradiation. 


\section{2. Degradation of Tartrazine (measurement 10 minutes after irradiation)}

Figure 4, Figure 5 and Figure 6 show a gradual decrease of Tartrazine solution absorbance of different concentrations for different $\mathrm{pH}$ values. The samples of initial concentration $10^{-4} \mathrm{M}$ can only withstand dose up to $100 \mathrm{~Gy}$. After this dose, the Tartrazine residual concentration was hardly detected by the spectrophotometer. The other two higher concentrations $\left(5 \times 10^{-4}\right.$ and $\left.10^{-3} \mathrm{M}\right)$ can survive up to $500 \mathrm{~Gy}$. The response to dose with respect to $\mathrm{pH}$ is similar for all concentrations studied. It can be observed that as initial $\mathrm{pH}$ increases, bleaching increases. I.e., degradation oxidative processes are more efficient as solution becomes more alkaline. However, the before- irradiation and after-irradiation $\mathrm{pH}$ values for each sample have not significantly changed. This means that $\mathrm{pH}$ parameter is a catalytic one and does not involve in the oxidative reaction. This important phenomenon will pearly be studied latter.

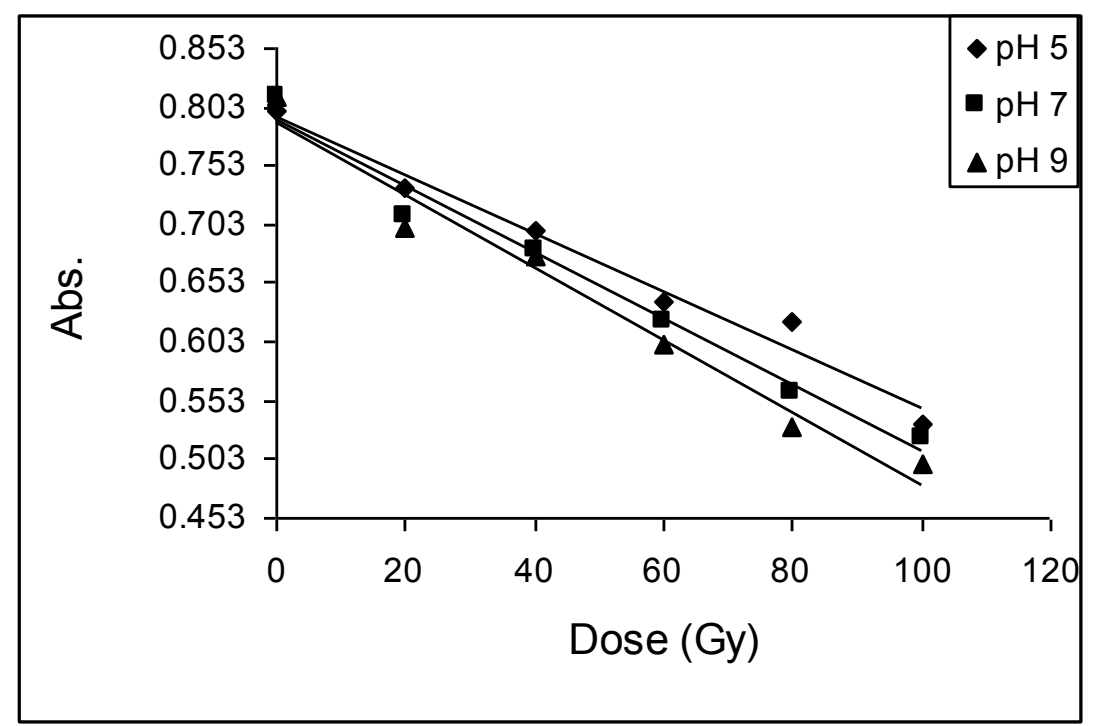

Figure 4. Tartrazine of concentration $10^{-4} \mathrm{M}$ at $\mathrm{pH}(5,7$ and 9).

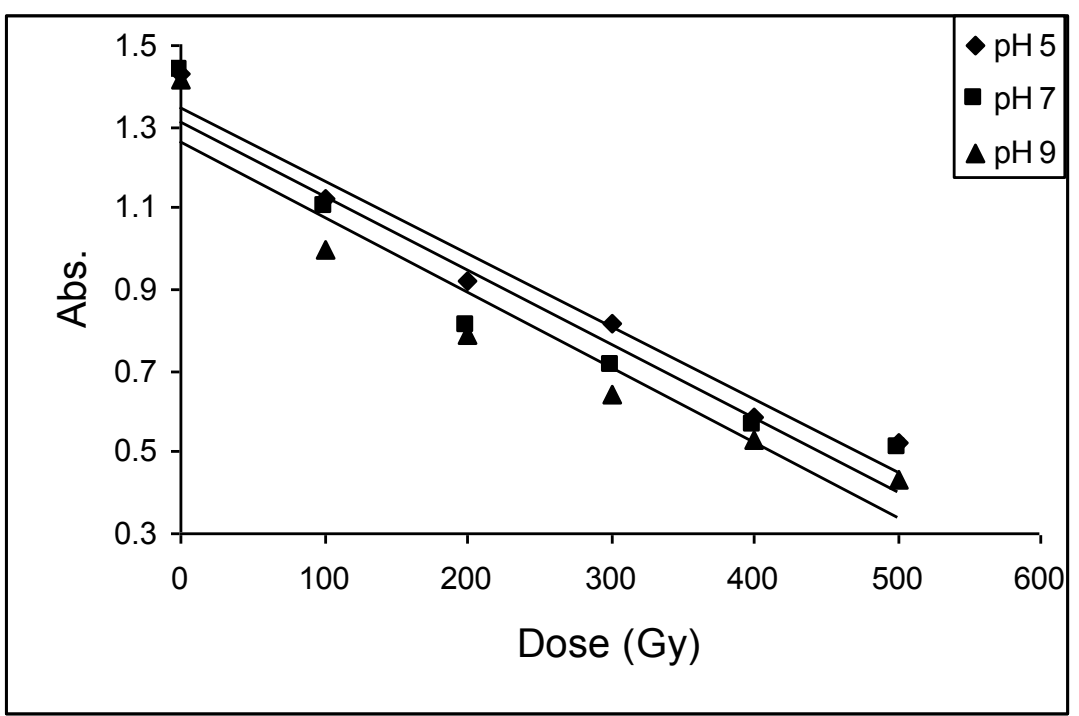

Figure 5. Tartrazine of concentration $5 \times 10^{-4} \mathrm{M}$ at $\mathrm{pH}(5,7$ and 9$)$. 


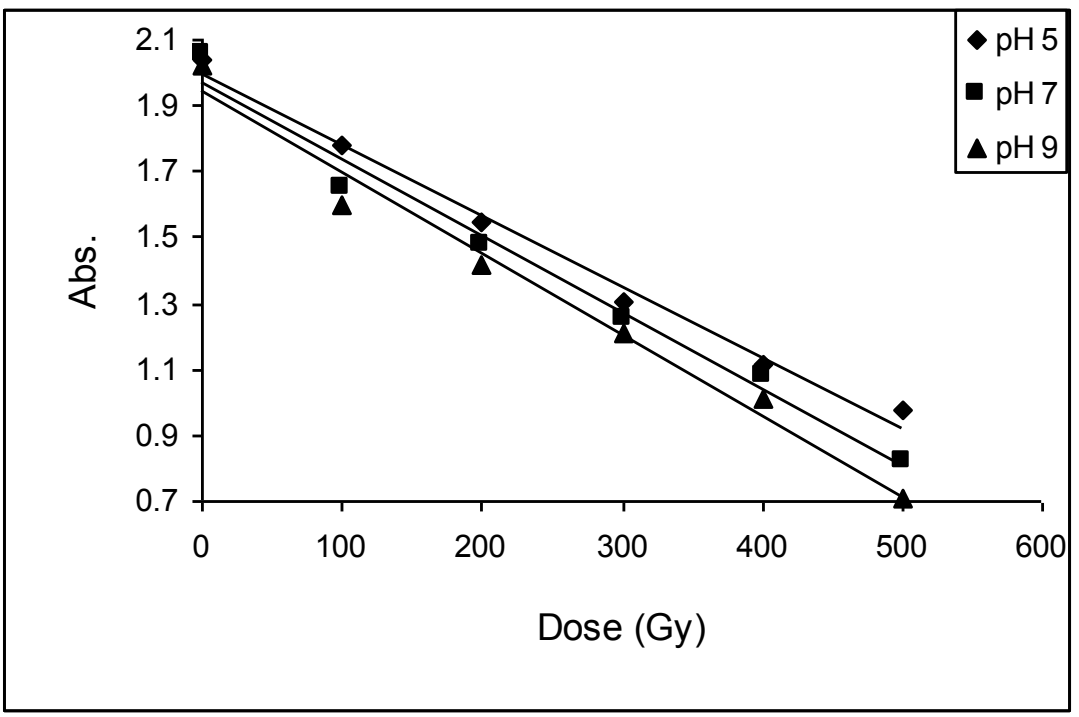

Figure 6. Tartarzine of concentration $10^{-3} \mathrm{M}$ at $\mathrm{pH}(5,7$ and 9).

Linear regressions of data give the equations that represent the linear fitted absorbance response to dose (absorption against dose). It is summarized in Table 1. To select the best conditions at which this dosimeter properly work, the correlation factor $(r)$ was regarded. By revising the different values of $r$, it can be concluded that the sample of concentration of $10^{-3}$ $\mathrm{M}$ with $\mathrm{pH} 5$ is the preferred one to apply. Although this $\mathrm{pH}$ condition is less sensitive to radiation compared to the other two $\mathrm{pH}$ conditions, its stability with doses (higher $r$ ) still prefer it to apply especially as the absorption response is not that much different from the other two $\mathrm{pH}$ conditions.

Table 1. Linear equations represent the linear absorbance response to dose for different initial concentrations and $\mathrm{pH}$ values.

\begin{tabular}{|c|c|c|c|c|c|}
\hline \multicolumn{2}{|c|}{ Post irradiation, 24 hours } & \multicolumn{2}{|c|}{ Directly after irradiation } & \multirow{2}{*}{$\begin{array}{c}\text { Initial } \\
\text { pH }\end{array}$} & \multirow{2}{*}{$\begin{array}{c}\text { Initial } \\
\text { concentration } \\
\text { (M) }\end{array}$} \\
\hline$r$ & Linear equation* & $r$ & Linear equation* & & \\
\hline 0.9928 & $y=-0.0026 x+0.7812$ & 0.9886 & $y=-0.0025 x+0.7946$ & 5 & \multirow{3}{*}{$10^{-4}$} \\
\hline 0.9863 & $y=-0.0030 x+0.7863$ & 0.9890 & $y=-0.0028 x+0.7913$ & 7 & \\
\hline 0.9763 & $y=-0.0033 x+0.7746$ & 0.9859 & $y=-0.0031 x+0.7894$ & 9 & \\
\hline 0.9742 & $y=-0.0019 x+1.3257$ & 0.9815 & $y=-0.0018 x+1.3462$ & 5 & \multirow{3}{*}{$5 \times 10^{-4}$} \\
\hline 0.9527 & $\mathrm{y}=-0.0019 x+1.2733$ & 0.9588 & $y=-0.0018 x+1.3104$ & 7 & \\
\hline 0.9561 & $\mathrm{y}=-0.0020 \mathrm{x}+1.2402$ & 0.9576 & $y=-0.0018 x+1.2627$ & 9 & \\
\hline 0.9747 & $y=-0.0024 x+1.9249$ & 0.9949 & $y=-0.0021 x+1.9976$ & 5 & \multirow{3}{*}{$10^{-3}$} \\
\hline 0.9728 & $y=-0.0026 x+1.9054$ & 0.9909 & $y=-0.0023 x+1.9678$ & 7 & \\
\hline 0.9635 & $y=-0.0026 x+1.8521$ & 0.9907 & $y=-0.0024 x+1.9402$ & 9 & \\
\hline
\end{tabular}

* y represents Absorption and x represents dose (Gy). 
The sensitivity of solutions (sensitivity: the absorbance change, $\Delta$ Abs., per unit dose, Gy) is an important factor to discuss. For each sample, the sensitivity is the slope of its equation, Table 1 . Change of sensitivity with respect to change of concentration and $\mathrm{pH}$ are given in Figure 7 and Figure 8 respectively.

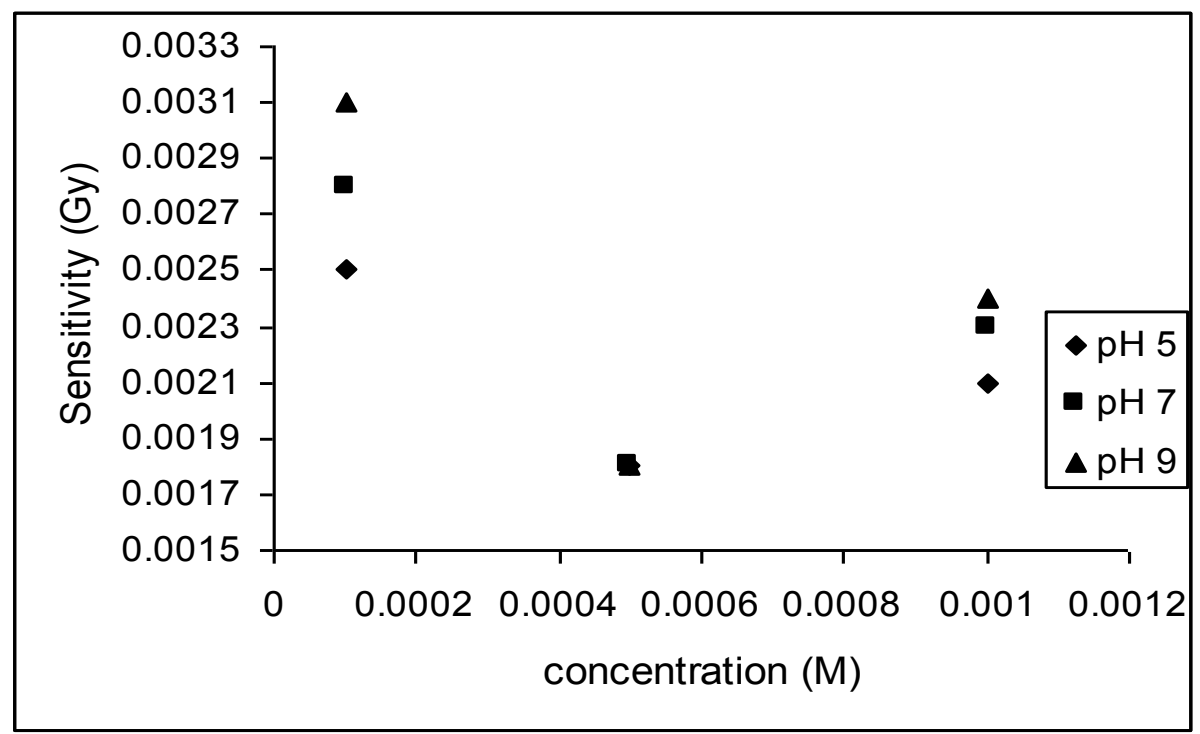

Figure 7. Dependence of sensitivity on the concentration of Tartrazine solution.

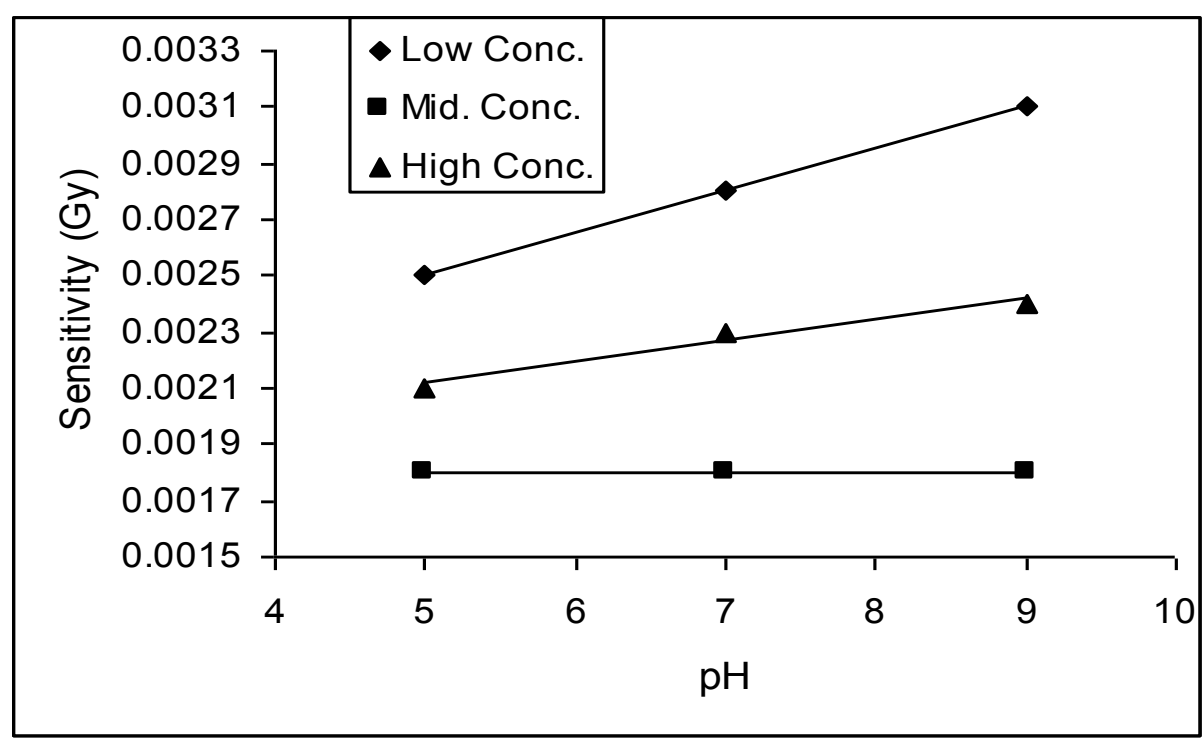

Figure 8. Dependence of sensitivity on the $\mathrm{pH}$ value of Tartrazine solution.

From Figure 7, the change of sensitivity is not regular which direct the user to carefully study the concentration to be used as an independent case, i.e. each concentration has its behavior towards irradiation. On the contrary, from Figure 8, the change of sensitivity is regular and this suggests that solution behavior can be predicted for different $\mathrm{pH}$ values other than studied ones. It is worthy to mention, in general, that sensitivity represents the rate of degradation with respect to dose and this rate increases with $\mathrm{pH}$ increase. This suggests a 
faster degradation at ultimately higher $\mathrm{pH}$ values (12-14) which enable user to apply this dosimeter for very low gamma doses.

\section{3. Post Irradiation Degradation (measurement 24 hours after irradiation)}

Determination of degradation of after a lag time is a stability test [18,19]. It is performed to find to what degree the solution change with time that may affect the measurements. The degradation of samples after 24 hours is shown in Figure 9, Figure 10, and Figure 11. In general, all post-irradiation samples show more bleaching compared to after-irradiation. Sample prepared at $\mathrm{pH}$ 9, for all concentrations studied, still shows more bleaching than those prepared at $\mathrm{pH} 7$ and 5 and this observation is similar to after-irradiation measurements.

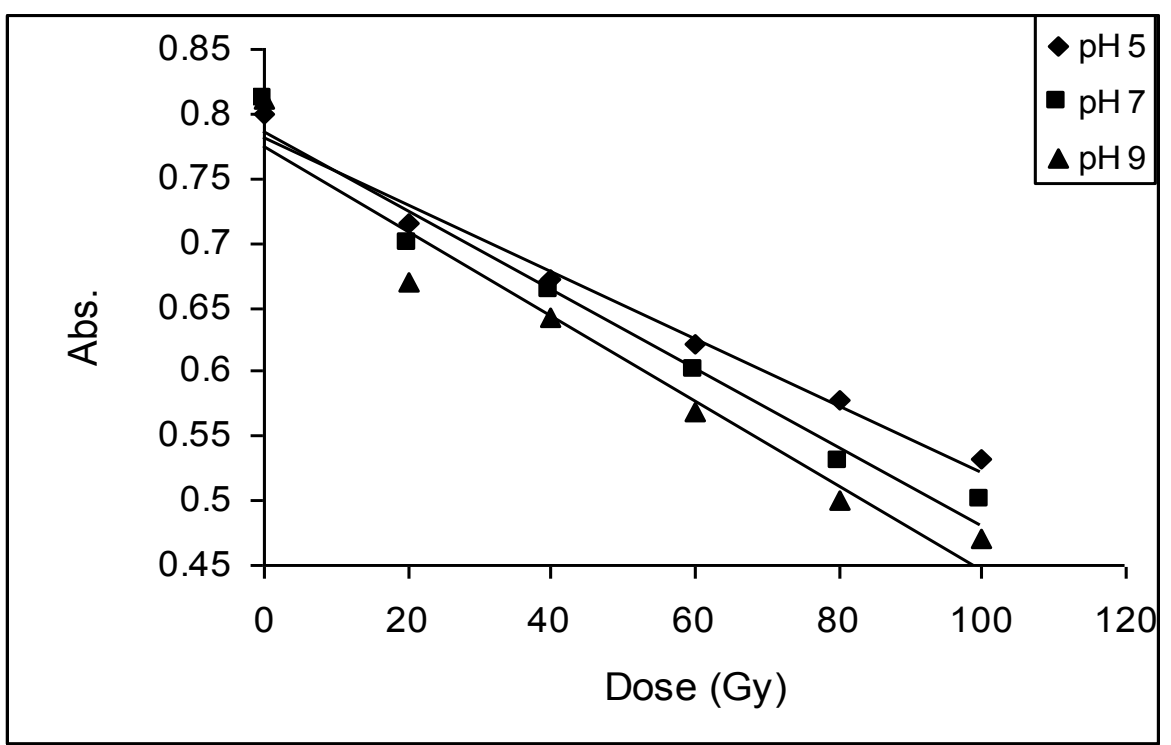

Figure 9. Post irradiation Tartrazine of concentration $10^{-4} \mathrm{M}$ after 24 hours of primary irradiation at different $\mathrm{pH}$.

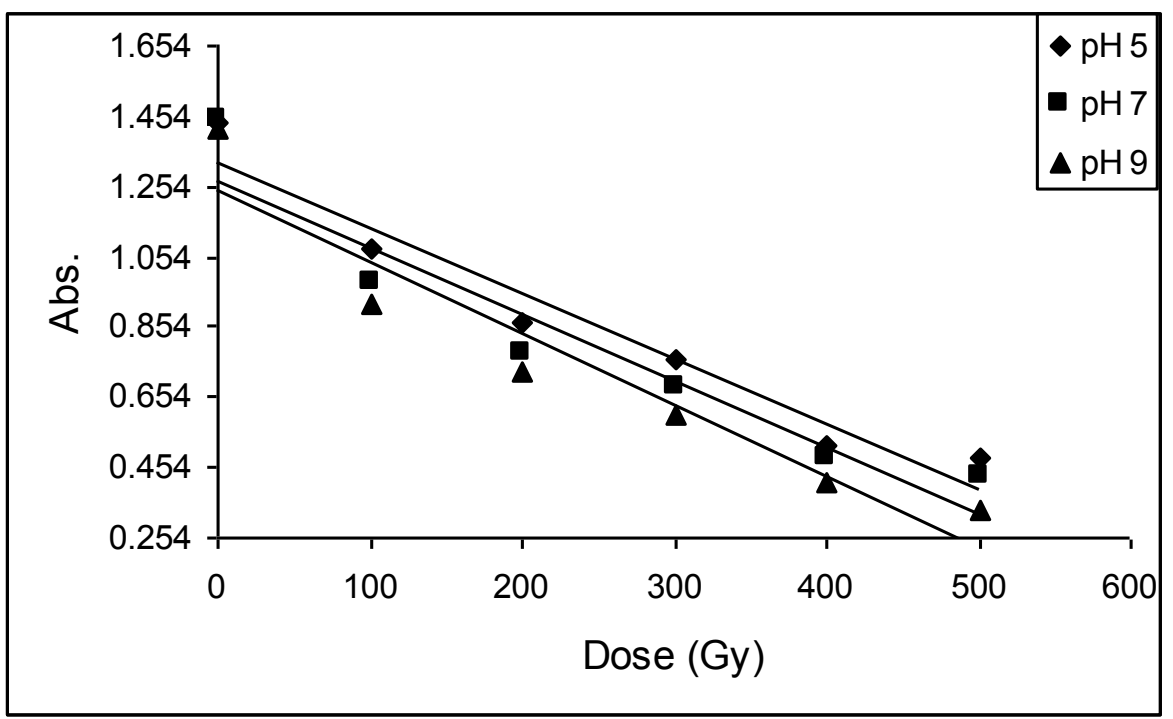

Figure 10. Post irradiation Tartrazine of concentration $5 \times 10^{-4} \mathrm{M}$ after 24 hours at different $\mathrm{pH}$. 


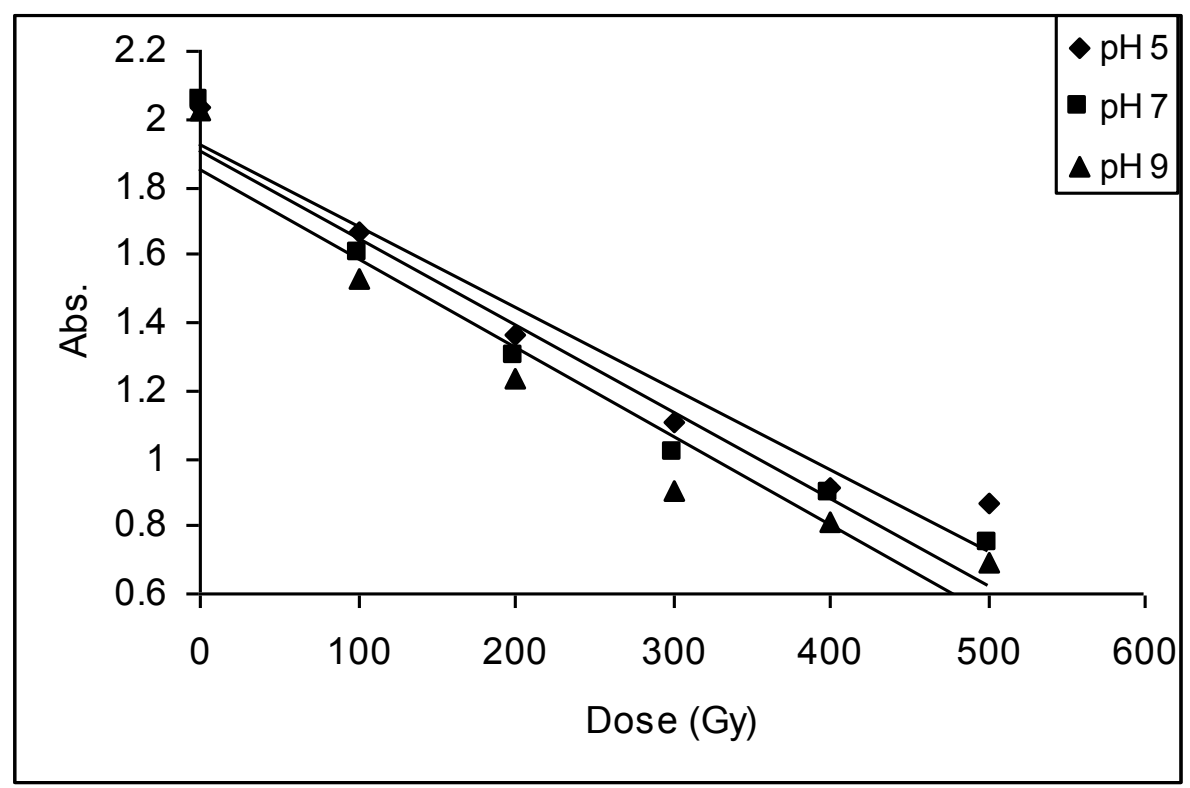

Figure 11. Post irradiation Tartrazine of concentration $10^{-3} \mathrm{M}$ after 24 hours at different $\mathrm{pH}$

For concentrations $5 \times 10^{-4} \mathrm{M}$ and $10^{-3} \mathrm{M}$ which subjected to doses up to $500 \mathrm{~Gy}$, the former shows more degradation.

Again, linear regressions of data give the absorption against dose equations. It is summarized in Table 1. By revising the different values of $r$, the best sample to apply is that of concentration of $10^{-4} \mathrm{M}$ with $\mathrm{pH}$ 5. The sensitivities are the slopes of equations, Table (1). Change of sensitivity with respect to change of concentration and $\mathrm{pH}$ are given in Figure 12 and Figure 13 respectively.

From Figure 12, the change of sensitivity is not regular (reasonably as in the previous case) and careful selection of concentration has to be considered. From Figure 13, the change of sensitivity is regular and indicates a good prediction of degradation as $\mathrm{pH}$ changes.

Percentages difference, PD \%, of absorption between samples of "directly after irradiation" and "post irradiation, 24 hours" are given in Table (2). From table, no consistency or a trend can be observed. This suggests careful dealing with "post irradiation" data with respect to "directly after irradiation". However, in general an extra degradation of 5-6\%, on average can be considered for the 24 hours lag effect.

Table 2. Percentages difference, PD \%, of Absorption between samples of "directly after irradiation" and "post irradiation, 24 hours".

\begin{tabular}{|c|c|c|c|c|c|c|c|c|c|c|}
\hline \multicolumn{9}{|c|}{ PD\% } & \multirow{2}{*}{$\begin{array}{c}\text { Initial } \\
\mathrm{pH}\end{array}$} & \multirow{2}{*}{$\begin{array}{c}\text { Initial } \\
\text { concentration } \\
\text { (M) }\end{array}$} \\
\hline $\begin{array}{l}500 \\
\text { Gy }\end{array}$ & $\begin{array}{l}400 \\
\text { Gy }\end{array}$ & $\begin{array}{l}300 \\
\text { Gy }\end{array}$ & $\begin{array}{c}200 \\
\text { Gy }\end{array}$ & $\begin{array}{l}100 \\
\text { Gy }\end{array}$ & $\begin{array}{l}80 \\
\text { Gy }\end{array}$ & $\begin{array}{l}60 \\
\text { Gy }\end{array}$ & $\begin{array}{l}40 \\
\text { Gy }\end{array}$ & $\begin{array}{l}20 \\
\text { Gy }\end{array}$ & & \\
\hline- & - & - & - & 0.2 & 5.5 & 2.2 & 3.3 & 2.5 & 5 & \multirow{3}{*}{$10^{-4}$} \\
\hline- & - & - & - & 2.6 & 3.7 & 2.4 & 2.4 & 1.2 & 7 & \\
\hline- & - & - & - & 3.7 & 0.5 & 3.8 & 4 & 3.7 & 9 & \\
\hline 3.0 & 4.9 & 3.5 & 3.3 & 2.9 & - & - & - & - & 5 & $5 \times 10^{-4}$ \\
\hline
\end{tabular}




\begin{tabular}{|l|c|c|c|c|c|c|c|c|c|c|}
\hline 5.6 & 6.1 & 2.3 & 2.2 & 8.3 & - & - & - & - & 7 & \\
\hline 7.2 & 8.6 & 3.0 & 3.9 & 5.6 & - & - & - & - & 9 & \\
\hline 5.5 & 10.0 & 9.8 & 8.8 & 5.4 & - & - & - & - & 5 & \multirow{2}{*}{$10^{-3}$} \\
\cline { 1 - 7 } 3.4 & 9.3 & 11.9 & 8.6 & 2.4 & - & - & - & - & 7 & \multirow{2}{*}{10} \\
\hline 1.0 & 9.9 & 15.3 & 9.4 & 3.5 & - & - & - & - & 9 & \\
\hline
\end{tabular}

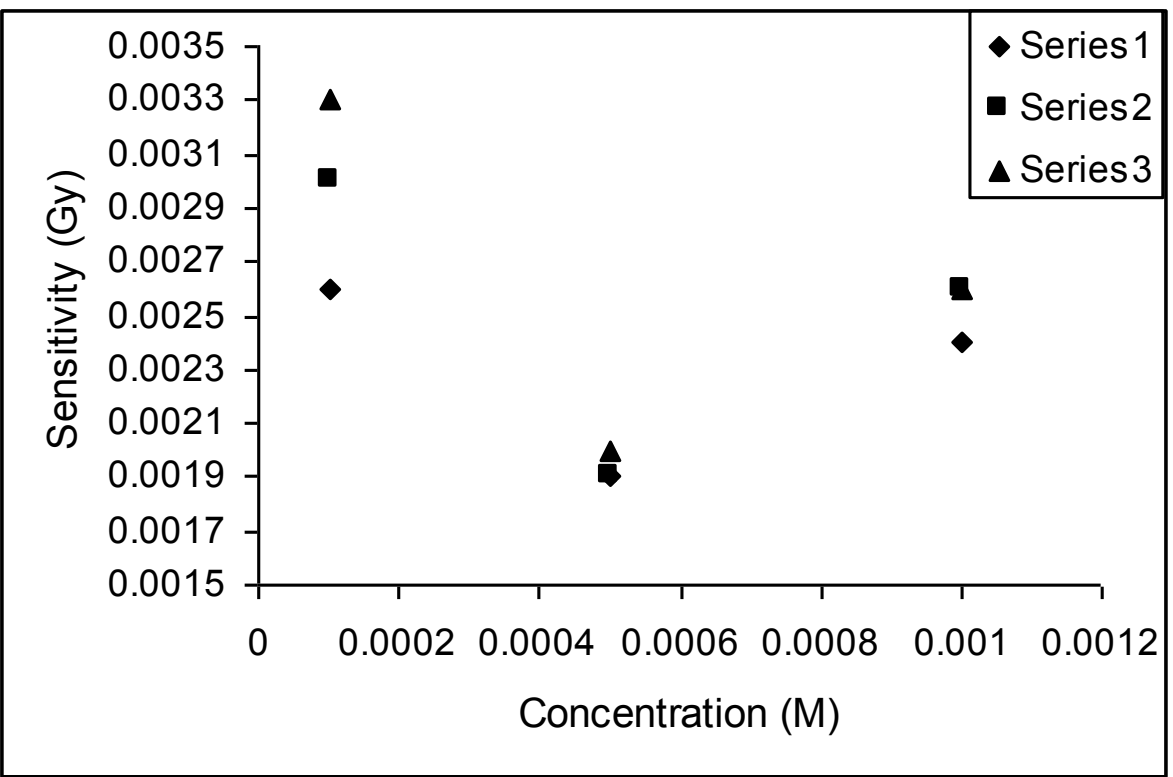

Figure 12. Dependence of sensitivity on the concentration of Tartrazine solution (Post irradiation).

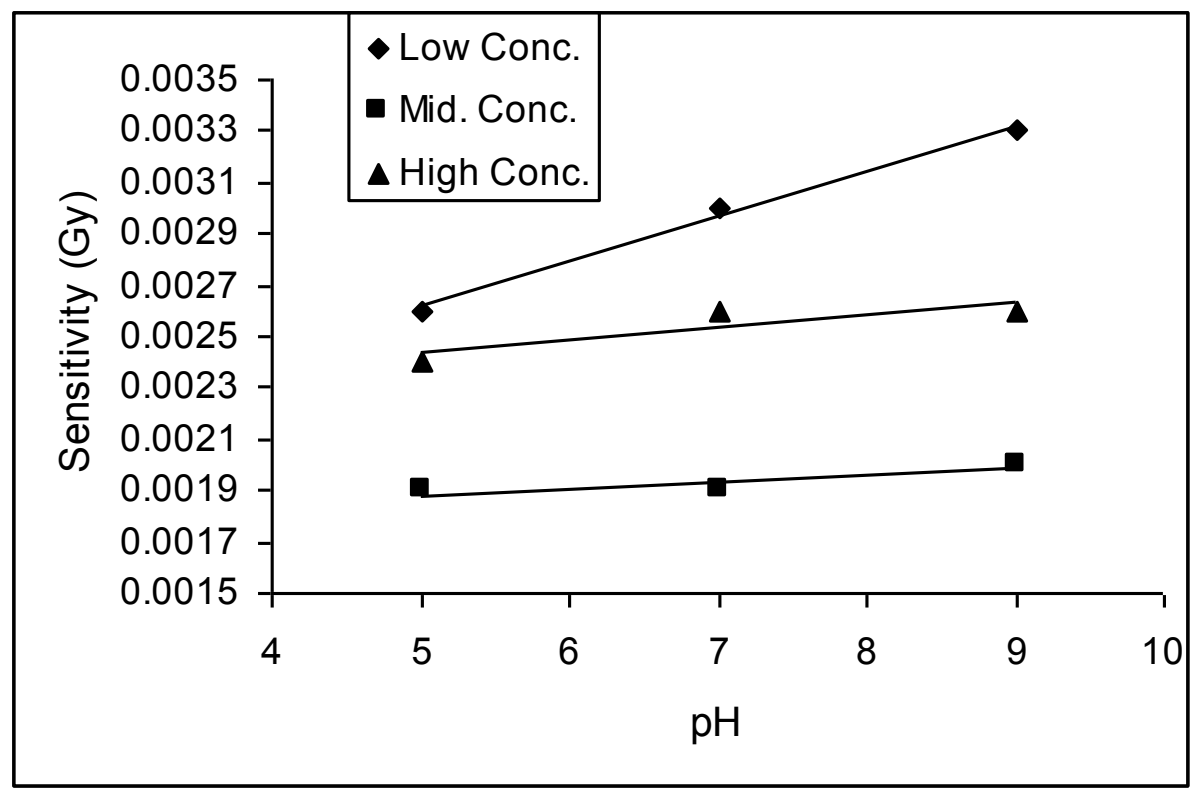

Figure 13. Dependence of sensitivity on the $\mathrm{pH}$ value of Tartrazine solution (Post irradiation). 


\section{CONCLUSIONS}

Tartarzine aqueous solution with different concentrations $\left(10^{-4}, 5 \times 10^{-4}\right.$ and $\left.10^{-3} \mathrm{M}\right)$ at different $\mathrm{pH}$ values $(5,7$ and 9$)$ were subjected to gamma irradiation. The results showed that Tartrazine degradated gradually and linearly, to some extant, with increasing gamma dose. In general, as solution-initial $\mathrm{pH}$ increases, the rate of bleaching increases. Moreover the $\mathrm{pH}$ values did not change after irradiation due to degradation of Tartarzine and consequently the stability of this solution can be suggested. Increase of Tartarzine-concentration causes more span of dose within which Tartarzine solution is susceptible to gamma radiation. The postirradiated effect (24 hours) causes 5-6\% more bleaching on average. The change of sensitivity of Tartarzine solution is regular with $\mathrm{pH}$ values but Tartarzine-concentration does not show the same regularity. According to sensitivity study, faster degradation of Tartarzine (i.e. with low doses) is significantly probable at high $\mathrm{pH}$ values (e.g. in 12-14 range). Tartrazine is a promising dosimeter when concentration is considered with care.

\section{References}

[1] A.S. Özen, V. Aviyente, R. A. Klein, The Journal of Physical Chemistry A 107 (2003) 4898-4907.

[2] C. M. Földváry, L. Wojnárovits, Radiation Physics and Chemistry 76 (2007) 14851488 .

[3] M. A. Rauf, S. S. Ashraf, Journal of Hazardous Materials 166 (2009) 6-16.

[4] M. Montazer, S. Morshedi, Journal of Industrial and Engineering Chemistry 20 (2014) 83-90.

[5] J. He, W. Ma, J. He, J. Zhao, J. C. Yu, Applied Catalysis B: Environmental 39 (2002) 211-220.

[6] Z. Ajji, Radiation Measurements 41 (2006) 438-442.

[7] A. A. Al Zahrany, K. A. Rabaeh, A. A. Basfar, Radiation Physics and Chemistry 80 (2011) 1263-1267.

[8] M. F. Barakat, K. El-Salamawy, M. El-Banna, M. Abdel-Hamid, A. Abdel-Rehim Taha, Radiation Physics and Chemistry 61 (2001) 129-136.

[9] J. H. Ramirez, C. A. Costa, L. M. Madeira, Catalysis Today 107-108 (2005) 68-76.

[10] R. Liu, H. M. Chiu, C.-S. Shiau, R.Y.-L. Yeh, Y.-T. Hung, Dyes and Pigments 73 (2007) 1-6.

[11] J.-H. Sun, S.-P. Sun, G.-L. Wang, L.-P. Qiao, Dyes and Pigments 74 (2007) 647-652.

[12] V. K. Gupta, R. Jain, A. Nayak, S. Agarwal, M. Shrivastava, Materials Science and Engineering: C 31 (2011) 1062-1067.

[13] P. Oancea, V. Meltzer, Journal of the Taiwan Institute of Chemical Engineers 44 (2013) 990-994.

[14] T. G. Solomons, C. Fryhle, Organic chemistry, 2000, John Wiley \& Sons, Inc., USA. 
[15] A. Aguedach, S. Brosillon, J. Morvan, E. K. Lhadi, Applied Catalysis B: Environmental 57 (2005) 55-62.

[16] C. G. Silva, W. Wang, J. L. Faria, Journal of Photochemistry and Photobiology A: Chemistry 181 (2006) 314-324.

[17] S. Meriç, D. Kaptan, T. Ölmez, Chemosphere 54 (2004) 435-441.

[18] B. Whittaker, M. Watts, S. Mellor, M. Heneghan, Some parameters affecting the radiation response and post-irradiation stability of red 4034 perspex dosimeters, 1984 , 293-305.

[19] A. Tchen, C. L. Greenstock, A. Trivedi, Radiation Protection Dosimetry 46 (1993) 119121.

[20] Sasenarine Harichan, Vishwa Nath Verma, International Letters of Chemistry, Physics and Astronomy 2 (2013) 11-17. 